\title{
Detection of bearing defects in three-phase induction motors using Park's transform and radial basis function neural networks
}

\author{
IZZET Y ÖNEL, K BURAK DALCI and İBRAHIM SENOL \\ Yildiz Technical University, Electrical-Electronics Faculty, Electrical Engineering \\ Department, 34349 Besiktas, Istanbul, Turkey \\ e-mail: $\{$ ionel,dalci,senol $\} @$ yildiz.edu.tr
}

MS received 15 March 2005

\begin{abstract}
This paper investigates the application of induction motor stator current signature analysis (MCSA) using Park's transform for the detection of rolling element bearing damages in three-phase induction motor. The paper first discusses bearing faults and Park's transform, and then gives a brief overview of the radial basis function (RBF) neural networks algorithm. Finally, system information and the experimental results are presented. Data acquisition and Park's transform algorithm are achieved by using LabVIEW and the neural network algorithm is achieved by using MATLAB programming language. Experimental results show that it is possible to detect bearing damage in induction motors using an ANN algorithm.
\end{abstract}

Keywords. Induction motor; stator current; bearing damage; Park's transform; RBF neural network.

\section{Introduction}

Induction motors are frequently used in industrial applications in a wide range of operating areas, due to their simple and robust structure, and low production costs. The reliability of an induction motor is of paramount importance in industrial, commercial, aerospace and military applications. Bearings play an important role in the reliability and performance of all motor systems. Due to the close relationship between motor system development and bearing assembly performance, it's difficult to imagine the progress of modern rotating machinery without consideration of the wide application of bearings. In addition, faults arising in motors are often linked to bearing faults. The results of various studies show that bearing problems account for over $40 \%$ of all machine failures (Schoen 1995).

In many situations, vibration monitoring methods are utilized to detect the presence of an incipient bearing failure. Vibration monitoring is a reliable tool for bearing failures. The vibration data typically contain fault signatures and salient fault features because of the direct measurement of the critical signal and placement of the vibration sensor. However, placing a sensing device on the motor might not be possible or practical in many applications, 


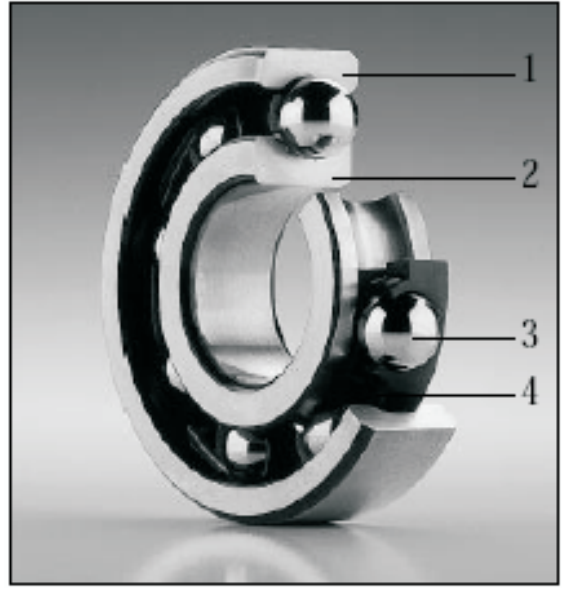

Figure 1. Parts of a deep groove ball bearing (6204ZZ). 1: Outer race, 2: inner race, 3: ball, 4: cage.

especially for a facility that employs a large number of electrical machines. In military and aerospace applications, large electromachine systems are often equipped with mechanical sensors. Primarily vibration sensors are based on proximity probes. These are delicate, too expensive for industrial systems and economically not viable for most customers. This is why, in spite of using vibration methods, it has been suggested that stator current monitoring can provide same indications without requiring access to the motor body (Kliman \& Stein 1992). On the other hand, stator current is readily available in many applications, and is usually measured for motor protection. Therefore, current-based fault detection has become an attractive area for bearing condition monitoring. Many papers have been published presenting methods for indication of these faults by use of stator current measurement (Kliman \& Stein 1990, 1992; Schoen et al 1995; Benbouzid et al 1999; Lindh et al 1999; Riley et al 1999; Yazıc1 \& Kliman 1999; Levent \& Devaney 2001).

In the present paper, some experiments are presented using motor current signature analysis (MCSA) that clarify that using the Park transform to indicate an outer race defect of ball bearing is reliable. Also, this paper demonstrates an ANN which can detect bearing defects on induction motors.

\section{Bearing structural defects}

Rolling element bearings generally consist of two rings, an inner and an outer ring, between which a set of balls or rollers rotate in raceways. Under normal operating conditions of balanced load and good alignment, fatigue failure begins with a small fissure, located between the surface of the raceway and the rolling elements, which gradually propagate to the surface, generating detectable vibrations and increasing noise levels (Eschmann et al 1958). Continued stress causes fragments of the material to break loose producing a localized fatigue phenomena known as flaking or spalling (Riddle 1955). Once started, the affected area expands rapidly contaminating the lubrication and causing localized overloading over the entire circumference of the raceway (Eschmann et al 1958). Eventually, the failure results in rough running of the bearing. While this is the normal mode of failure in rolling element bearings, there are many other conditions which reduce time of bearing failure. These external sources include contamination, corrosion, improper lubrication, improper installation or brinelling. 
Contamination and corrosion frequently accelerate bearing failures because of the harsh environments present in most industrial settings. Dirt and other foreign matter that is commonly present often contaminate bearing lubricant. The abrasive nature of these minute particles, whose hardness can vary from relatively-soft to diamond-like, cause pitting and sanding actions that give way to measurable wear of the balls and raceways (Riddle 1955). Bearing corrosion is produced by the presence of water, acids, deteriorated lubrication and even perspiration from careless handling during installations (Riddle 1955; Eschmann et al 1958). Once the chemical reaction has advanced sufficiently, particles are worn off resulting in the same abrasive action produced by bearing contamination. Improper lubrication includes both under- and over-lubrication. In either case, the rolling elements are not allowed to rotate on the designed oil film, causing increased levels of heating. Excessive heating causes the grease to break down which reduces its ability to lubricate the bearing elements and thus accelerates the failure process.

Installation problems are often caused by improperly forcing the bearing onto the shaft or in to the housing. This produces physical damage in the form of brinelling or false brinelling of the raceways which leads to premature failure. Misalignment of the bearing, which occurs in the four ways depicted in figure 2, is also a common result of defective bearing installation. The most common of these is caused by tilted races (Riddle 1955).

Brinelling is the formation of indentations in the raceways as a result of deformation caused by static overloading. While this form of damage is rare, a form of "false brinelling" occurs more often. In this case, the bearing is exposed to vibrations; even though lightly loaded bearings are less susceptible, false brinelling still happens and has even occurred during the transportation of uninstalled bearings (Eschmann et al 1958).

Regardless of the failure mechanism, defective rolling element bearings generate mechanical vibrations at the rotational speeds of each component. These characteristic frequencies, which are related to the raceways and the balls or rollers, can be calculated from the bearing dimensions and the rotational speed of the machine. Mechanical vibration analysis techniques are commonly used to monitor these frequencies in order to determine the condition of the bearing.

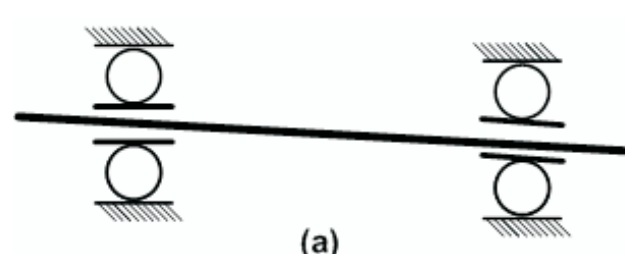

(a)

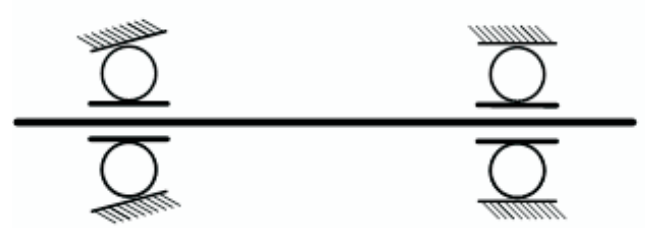

(c)

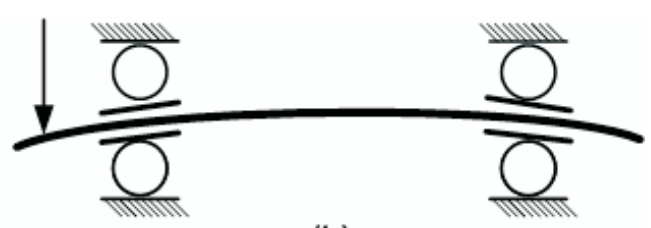

(b)

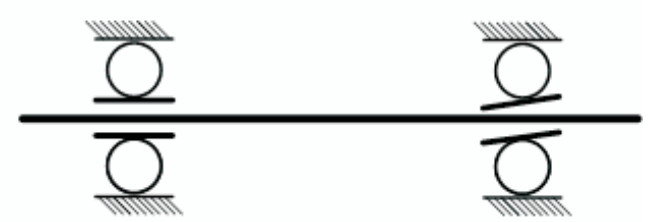

(d)

Figure 2. (a) Misaligment (out-of-line), (b) shaft deflection, (c) crooked or tilted outer race, (d) crooked or tilted inner race. 


\section{Park's vector approach}

In three-phase induction motors, the connection to the mains does not usually use the neutral. Therefore, the mains current has no homopolar component. A two-dimensional representation can then be used for describing three-phase induction motor phenomena, a suitable one being based on the current Park's vector (Nejjari 2000). As a function of mains phase variables $\left(i_{a}, i_{b}, i_{c}\right)$ the current Park's vector components $\left(i_{d}, i_{q}\right)$ are

$$
\begin{aligned}
& i_{d}=\sqrt{(2 / 3)} i_{a}-(1 / \sqrt{6}) i_{b}-(1 / \sqrt{6}) i_{c}, \\
& i_{q}=-(1 / \sqrt{2}) i_{b}-(1 / \sqrt{2}) i_{c} .
\end{aligned}
$$

Under ideal conditions, three-phase currents lead to a Park's vector with the following components:

$$
\begin{aligned}
& i_{d}=(\sqrt{6} / 2) I \cdot \sin \omega t, \\
& i_{q}=(\sqrt{6} / 2) I \cdot \sin (\omega t-(\pi / 2)),
\end{aligned}
$$

where $I$ is the maximum value of the supply phase current, $\omega_{s}$ the supply frequency and $t$ the time variable.

A pure sinusoidal signal makes a circular pattern centred at the origin of the coordinates. This is a very simple reference figure that allows the detection of abnormal conditions by monitoring the deviations of acquired patterns. In addition this pattern could be learnt by an artificial neural network, and thus faults could be detected automatically with this method (Nejjari \& Benbouzid 2000). There are several types of training algorithms suggested in the literature for fault delection of induction motors (Chow \& Yee 1991; Chow et al 2003).

\section{Radial basis function networks}

A schematic of the RBF network with $N$ inputs and a scalar output is given in figure 3 . The basic structure of the network is seen in this figure. The input nodes pass the input values to the connecting arcs, and the first layer connections are not weighted. Thus each hidden node receives each input value, unaltered. The hidden nodes are the radial basis function units. The transfer function for hidden nodes is nonmonotonic in contrast to the monotonic sigmoid function of backpropagation networks. The second layer of connections is weighted, and the output nodes are simple summations. The radial basis function network does not extend to more layers in as natural manner as backpropagation networks because of the different functions and parameters of the layers, but improved training and performance are directly related to this architecture (Leonard \& Kramer 1991).

There are $H$ nodes in the hidden layer of the network. The transfer function used is similar to the Gaussian density function:

$$
a_{h k}=\exp \left(-\left\|\hat{x}_{h}-x_{k}\right\|^{2} / \sigma_{h}^{2}\right)
$$

where $a_{h k}$ is the activation of the $h$ th unit in the hidden layer given the input $x_{k}$. Each node has associated with it $N+1$ parameters: $\hat{x}$, the $N$-dimensional position of the centre of the radial unit in the input space, and $\sigma$, a distance scaling parameter which determines over what 


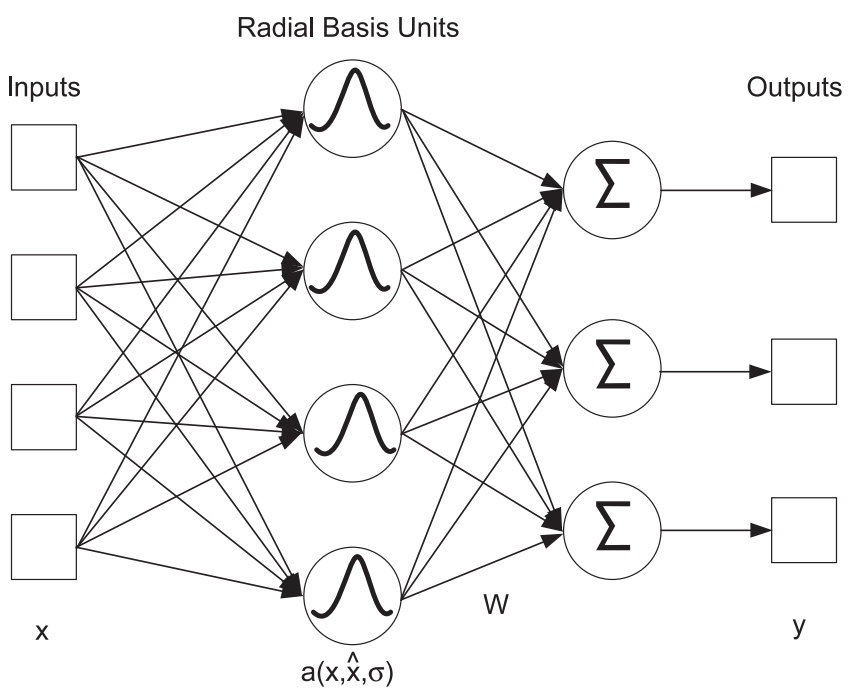

Figure 3. A radial basis function network architecture with nonmonotonic transfer function in hidden nodes, weighted connections in the second layer only, and summation units for output nodes.

distance in the input space the unit will have a significant influence. The parameter $\sigma$ has the same function as standard deviation in the standard normal probability distribution, although it is not estimated in the same way (Leonard \& Kramer 1991; Kolla \& Varatharasa 2000).

The connections in the second layer are weighted in the usual neural network manner. The output of the network $y$ is given by:

$$
y_{m}=\sum_{h=1}^{H} w_{m h} \cdot a_{h} .
$$

The training data set is formulated the same way for this network classifier as for the backpropagation network. The target output vector $T$ has a single " $l$ " in the position corresponding to the correct class and zeroes elsewhere. The training is done by minimizing the same objective function as before:

$$
E(\hat{x}, \sigma, w)=\sum_{k=1}^{K}\left\|y_{k}-T_{k}\right\|^{2}
$$

A single procedure analogous to backpropagation to optimize the error function would be difficult. However, the problem of training can be decomposed quite naturally. The parameters for radial basis function units are determined in three steps. First, the unit centres $\hat{x}$ are determined. Then the scaling parameters $\sigma_{h}$ are determined. Finally, the weighted connections of the second layer of the network are determined.

In practice the centres are chosen normally from the points or randomly. The key question is therefore how to select centres appropriately from the data set. A commonly used method to date is to choose arbitrarily some data points as centres. Apparently such a method cannot guarantee adequate performance because it may not satisfy the requirement that centres should suitably sample the input domain. Furthermore, in order to achieve a given performance, unnecessarily large RBF network may be required. This adds computational complexity (Chen et al 1991). 
Table 1. Rated parameters of the machine under test.

\begin{tabular}{lc}
\hline Power & $0.75 \mathrm{~kW}$ \\
Frequency & $50 \mathrm{~Hz}$ \\
Voltage $(\Delta / \Upsilon)$ & $220 / 380 \mathrm{~V}$ \\
Current $(\Delta / \Upsilon)$ & $3.4 / 1.95 \mathrm{~A}$ \\
Speed & $2780 \mathrm{rpm}$ \\
Pole pair $(p)$ & 1 \\
\hline
\end{tabular}

\section{System information}

\subsection{Stator current monitoring system}

The purpose of the monitoring system is to measure three-phase the induction motor stator current. The currents that flowing in three-phase of the induction motor, are sensed by a current transformer and they are sent to the National Instruments PCI-1200 data acquisition card that is connected to the PCI slot of the personal computer. The digitalized current signal is applied to the low pass current filter to remove the undesirable high frequency components that produce aliasing of the sampled signal. The LabVIEW programme converts the sampled signal that sampling frequency is $10 \mathrm{ksample} / \mathrm{sec}$, to $D$ and $Q$ domain using as Park's transform algorithm.

\subsection{Testing equipment}

In this study, a $0.75 \mathrm{~kW}$ two-pole induction motor AGM802A, whose parameters are given in table 1 , was used. The nominal current is $I_{N}=1.95 \mathrm{~A}$ when star connected to the $380 \mathrm{~V}$ network. The motor is loaded with a car alternator VDN10701118 whose $12 \mathrm{~V}$ DC output is applied to the variable resistive loads. The alternator, tacho generator and induction motor are connected together with steel coupling in the same alignment. The analog tacho generates the $90 \mathrm{~V}$ in $3000 \mathrm{rpm}$. Testing equipment is shown in figure 4.

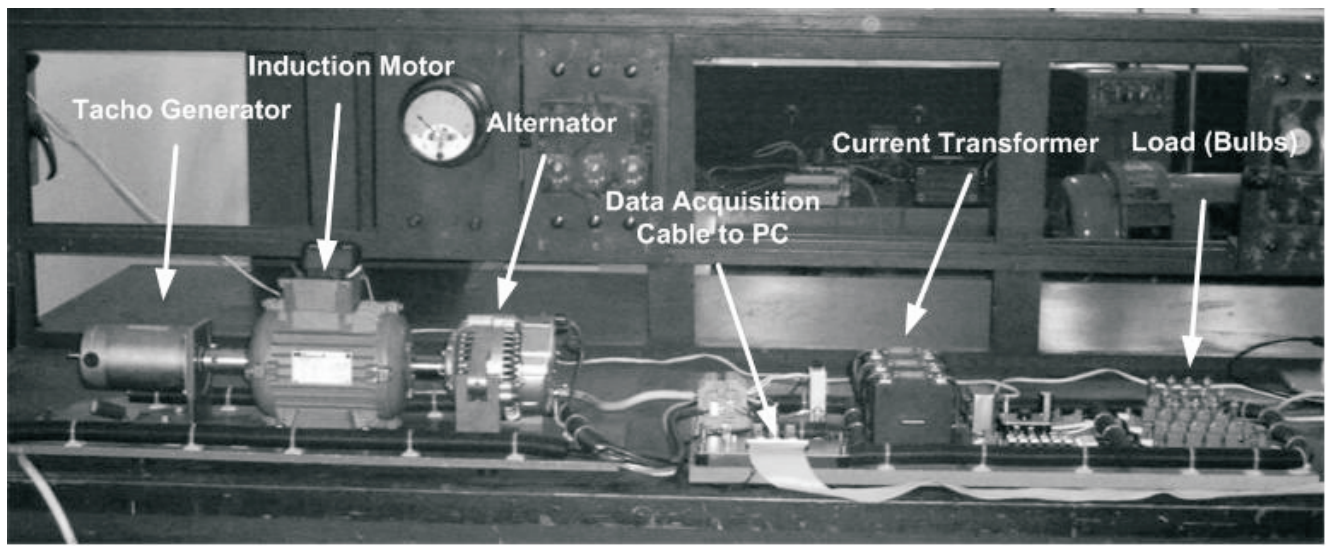

Figure 4. Test jig has two parts: Mechanical and electrical. The mechanical part consists of a tacho generator for speed measuring and an induction motor with bearing failure, and a car alternator to load the induction motor. Electrical part of the test jig has three parts: three current transformers, an outlet to the PC based-data acquisition card and bulbs that are used as load. 


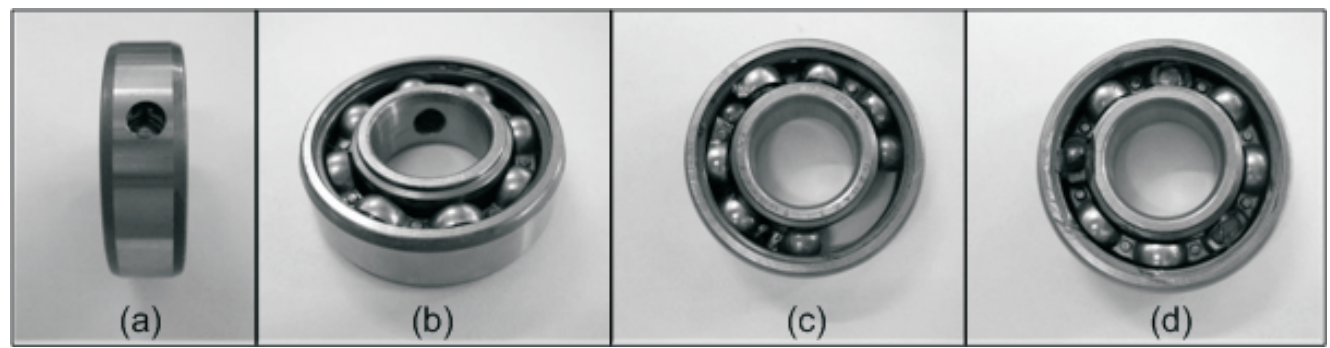

Figure 5. Four defective bearings that were used in experimental studies showing (a) outer race defect, (b) inner race defect, (c) cage defect, (d) ball defect.

The bearings of the induction motor are single row, deep groove ball bearings, type 6204.2ZR. Bearings have 8 balls each. Experiments were conducted on nine bearings: one of these is healthy and eight of bearings were defective (inner race, outer race, cage and ball defect) (figure 5).

\subsection{Measurement configuration}

Stator current was measured from the three-phases with current transformers whose transformation rate is $5 / 1$. A measurement configuration is illustrated in figure 6 . The induction motor currents are digitalized with a National Instrument's data acquisition card called PCI1200. The 1200 family devices are low-cost, multifunction I/O devices with up to $100 \mathrm{kS} / \mathrm{s}$, 12-bit performance on 8 single-ended or 4 differential analogue inputs. The 1200 family features digital triggering capability; three 16-bit, $8 \mathrm{MHz}$ counter/timers; two 12-bit analogue outputs; and 24 digital I/O lines (National Instruments 1998). The proposed LabVIEW program takes a signal in and performs Park's transform algorithm, and records this knowledge in the computer environment.

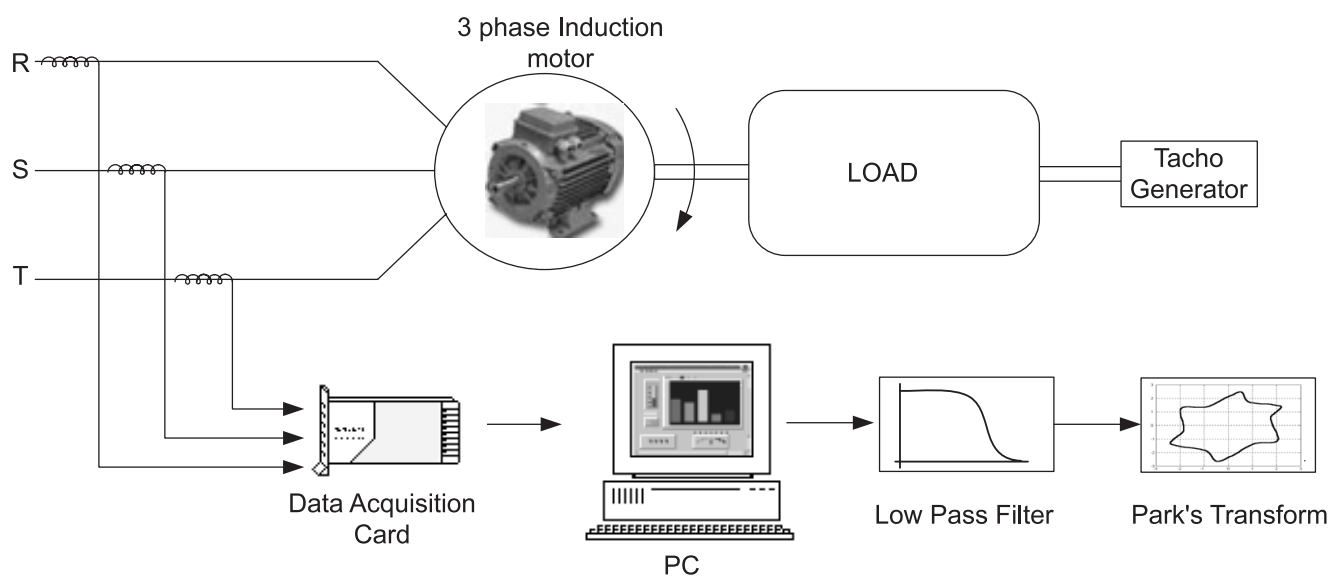

Figure 6. Measurement configuration block diagram. 


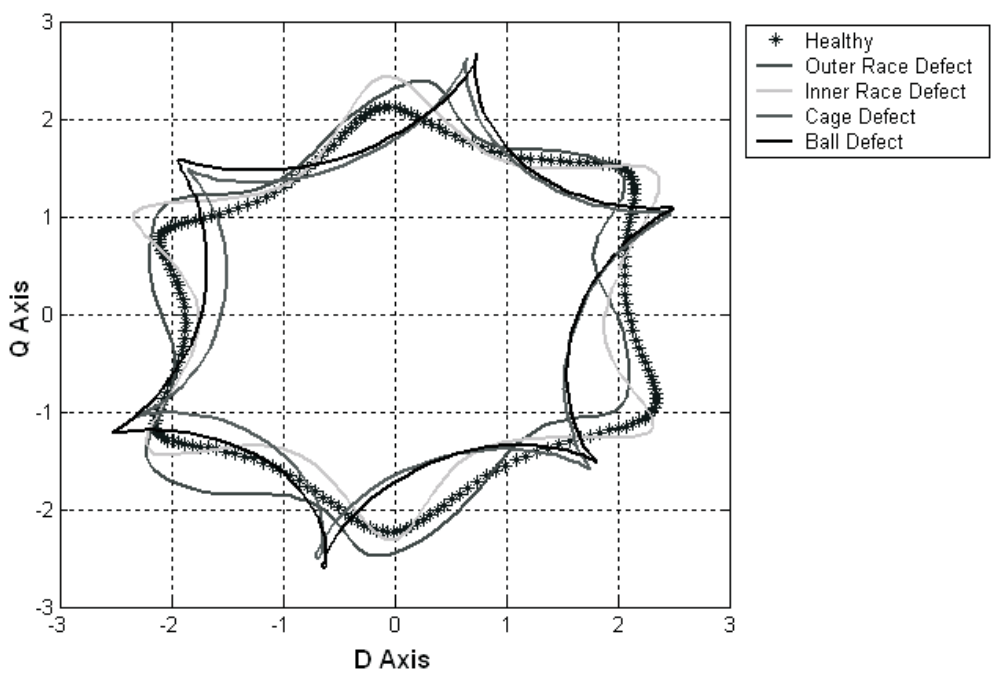

Figure 7. Variation of $D$ and $Q$ components of the stator current with healthy and faulty bearings.

\section{Experimental study}

In the Electrical Machines Laboratory of Yildı Teknik University, eight 6204.2ZR type bearings were defective in the outer race, inner race, cage and ball. While these were not realistic bearing failures, the artificial bearing faults produced similar effects on the stator current. Induction motor three-phase current was sampled and transferred to PC with a data acquisition card. Sampled data were applied to Park's transform to obtain $D$ and $Q$ axis components. Figure 7 shows the $D$ and $Q$ components variation of healthy and faulty motors.

In order to use the ANN for identifying induction motor fault and non-fault conditions, it is necessary to select proper inputs and outputs of the network, and train it with appropriate data. In this study, inputs are selected three-phase motor currents that are sampled at $10 \mathrm{kHz}$ frequency. Three-phase motor currents are applied to Park's transform and their $D$ and $Q$ component are obtained. There are 200 samples in a period of current waveform hence; the ANN has 400 input nodes. In addition, the ANN has one hidden layer and ten output neurons. The following figure shows the ANN structure.

To realize the RBF network structure, MATLAB programming language's Neural Network tool box was used. Training and test sessions were also done with the same tool box. The

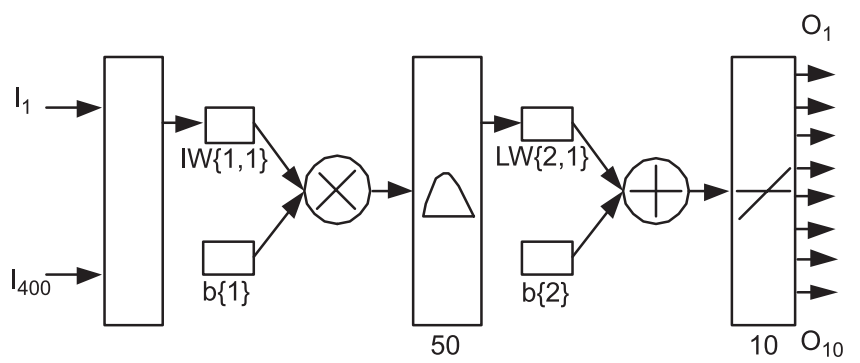

Figure 8. ANN structure which is used in the experimental study. 

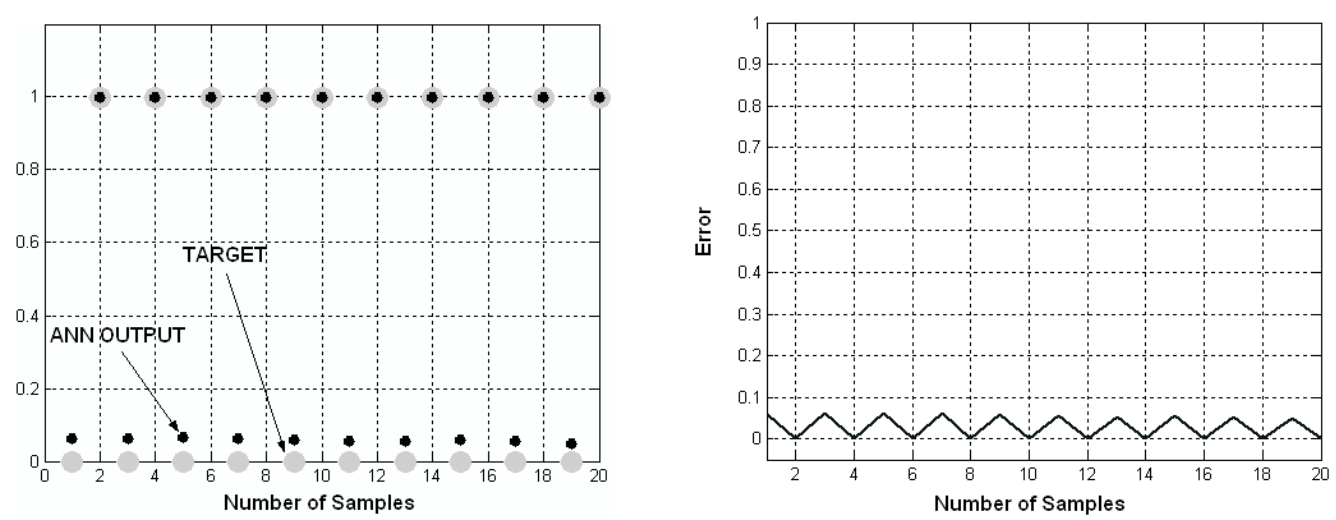

Figure 9. Variation of the ANN output, target and error with number of samples.

RBF network has 400 input nodes, 50 hidden neuron and 10 output nodes. The fault detection system output is obtained by diving 10, sum of the all outputs of the RBF network. Scaling factor is chosen as 2.5 manually. In the following figure shows the deviation of the network errors and targets-outputs by the number of samples. If the bearing is healthy, the ANN output should be 0 , and if the motor has a faulty bearing, the network output should be 1 . Experimental results may be seen in figures $9 a$ and b. 20 test data that are different from training data were used to measure network accuracy. The ANN outputs are very close to the target, furthermore it is the same for the faulty bearing. The maximum error is about 0.0634 .

\section{Conclusions}

Defective rolling element bearings generate eccentricity in the air gap with mechanical vibrations. The air gap eccentricities cause variations in the air gap flux density that produces visible changes in stator current. These changes are hard to determine in stator current waveform but using Park's transform could make it easier. This paper has described a new method to detect bearing faults in small induction motors using three-phase current of induction motor with Park's transform and RBF network algorithm. The diagnosis process was tested on a $0.75 \mathrm{~kW}$, squirrel-caged induction motor. ANN was trained, giving $100 \%$ correct prediction for training data. When ANN was presented a set of Park's vector pattern which have not been trained, the diagnosis system was found to provide very good performance.

\section{References}

Benbouzid M E, Vieira M, Theys C 1999 Induction motor' fault detection and localisation using stator current advanced signal processing techniques. IEEE Trans. Power Electron. 14: 14-22

Chen S, Cowan C F N, Grant P M 1991 Orthogonal least squares learning algorithm for radial basis function networks. IEEE Trans. Neural Networks 2: 302-309

Chow M-Y, Sharpe R N, Hung J C 1993a On the application and design of artificial neural networks for motor fault detection - Part I. IEEE Trans. Ind. Electron. 40: 181-188

Chow M-Y, Sharpe R N, Hung J C 1993b On the application and design of artificial neural networks for motor fault detection - Part II. IEEE Trans. Ind. Electron. 40: 189-196 
Chow M-Y, Yee S O 1991 Methodology for on-line incipient fault detection in single phase squirrel cage induction motors using artificial neural networks. IEEE Trans. Energy Conversion 6: 536-545

Eschmann P, Hasbargen L, Weigand K 1958 Ball and roller bearings: Their theory, design, and application (London: K G Heyden)

Kliman G B, Stein J 1990 Induction motor fault detection via passive current monitoring. In Proc. Int. Conf. Electrical Machines, pp 13-17

Kliman G B, Stein J 1992 Methods of motor current signature analysis. Elec. Mach. Power Syst. 20: 463-474

Kolla S, Varatharasa L 2000 Identifying three-phase induction motor faults using artificial neural networks. ISA Trans. 39: 433-439

Levent E, Devaney M J 2001 Motor bearing damage detection via wavelet analysis of the starting current moment. IEEE Instrumentation and Measurement Technology Conference, Hungary, Budapest

Leonard J A, Kramer M A 1991 Radial basis function networks for classifying process faults. IEEE Control Syst. Mag. 11: 31-38

Lindh T, Ahola J, Partanen J 1999 Evaluation of condition monitoring of bearings of $15 \mathrm{~kW}$ induction motor based on statistical stator current analysis. In Proc. Int. Conf. on Electrical Machines, Brugges, Belgium (CD-ROM)

National Instruments, Data Acquisition Basics Manual, 1998

Nejjari H, Benbouzid M E-H 2000 Monitoring and diagnosis of induction motors electrical faults using a current Park's vector pattern learning approach. IEEE Trans. Ind. Appl. 36: 730-735

Riddle J 1955 Ball bearing maintenance (Norman, OK: Univ. of Oklohama Press)

Riley C M, Lin B K, Habetler T G, Kliman G B 1999 Stator current harmonics and their causal vibrations: A preliminary investigation of sensorless vibration monitoring applications. IEEE Trans. Ind. Appl. 35: 94-99

Schoen R R, Habetler T G, Kamran F, Bartheld R G 1995 Motor bearing damage detection using stator current monitoring. IEEE Trans. Ind. Appl. 31: 1274-1279

Yazıcı B, Kliman G B 1999 An adaptive statistical time-frequency method for detection of broken bars and bearing faults in motors using stator current. IEEE Trans. Ind. Appl. 35: 442-452 